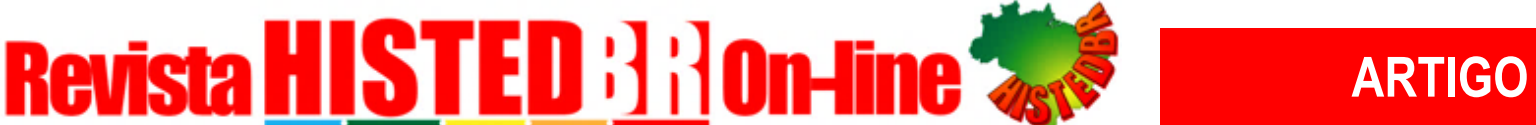

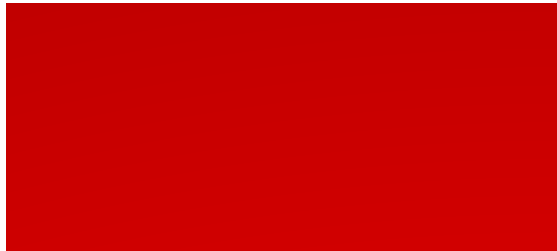

A Revista HISTEDBR On-line publica artigos resultantes de estudos e pesquisas científicas que abordam a educação como fenômeno social em sua vinculação com a reflexão histórica

Correspondência ao Autor Nome: Jairo Carvalho do Nascimento

E-mail: jcnascimento@uneb.br Instituição: Universidade do Estado da Bahia, Brasil

Submetido: 13/10/2019

Aprovado: $23 / 11 / 2020$

Publicado: 02/08/2021

doi> 10.20396/rho.v21i00.8657131 e-Location: e021038 ISSN: $1676-2584$

Como citar ABNT (NBR 6023): NASCIMENTO, J. C. do;

CASTRO, M. A. D. O currículo

decolonial e o combate ao racismo epistêmico. Revista HISTEDBR On-line, Campinas, SP, v. 21, p. 117, 2021. DOI:

10.20396/rho.v21i00.8657131.

Disponível em:

https://periodicos.sbu.unicamp.br/o js/index.php/histedbr/article/view/8 657131. Acesso em: 02 ago. 2021.

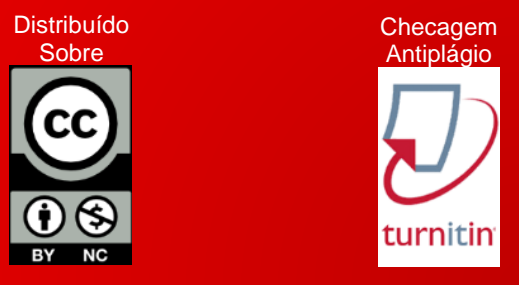

\section{O CURRÍCULO DECOLONIAL E O COMBATE AO RACISMO EPISTÊMICO}

\author{
(9Lattes Jairo Carvalho do Nascimento* \\ Universidade do Estado da Bahia

\section{(9) Lattes Maria Aparecida Dias Castro**} \\ Rede Municipal de Educação de Caetité
}

\section{RESUMO}

Este texto discute aspectos relacionados ao currículo como um campo de disputas de poder que se desenrola na ação prática. Problematiza as bases epistemológicas do currículo, ensejando uma travessia do eurocentrismo para ouvir as vozes que ressoam da América, da Ásia, da África e da diáspora negra, no intuito de dissipar o desconhecimento que nos rodeia, matriz de muitas ignorâncias e visões distorcidas sobre temáticas da história da Âfrica e da cultura afro-brasileira. É no âmbito dessa perspectiva que a decolonialidade se insere como uma possibilidade de transgredir as normas sobre o que deve ser ensinado, tendo em vista que o racismo epistemológico tem norteado a construção, disseminação e problematização de saberes no ambiente escolar. Destarte, provocar reflexões sobre a decolonialidade do currículo é uma estratégia para o combate ao racismo, pensado como fenômeno estruturante das relações sociais.

PALAVRAS-CHAVE: Currículo. Decolonialidade. Racismo epistemológico. 


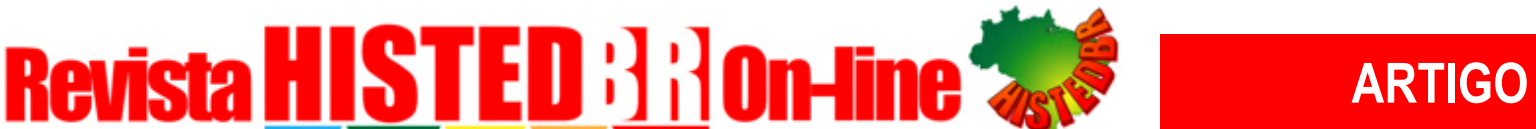 \\ THE DECOLONIAL CURRICULUM AND THE FIGHT AGAINST EPISTEMIC RACISM
}

\begin{abstract}
This text discusses aspects related to the curriculum as a field of power disputes that unfolds in practical action. It questions the epistemological bases of the curriculum, giving rise to a crossing of Eurocentrism to hear the voices that resound from America, Asia, Africa and the black diaspora, in order to dispel the ignorance that surrounds us, matrix of many ignorances and distorted views on themes of African history and afro-brazilian culture. It is within this perspective that decoloniality is inserted as a possibility of breaking the norms about what should be taught, considering that epistemological racism has guided the construction, dissemination and problematization of knowledge in the school environment. Thus, provoking reflections on the decoloniality of the curriculum is a strategy to combat racism, thought as a structuring phenomenon of social relations.
\end{abstract}

Keywords: Curriculum. Decoloniality. Epistemological racism.

\section{EL CURRÍCULUM DESCOLONIAL Y LA LUCHA CONTRA EL RACISMO EPISTÉMICO}

\begin{abstract}
Resumen
Este texto discute aspectos relacionados con el plan de estudios como un campo de disputas de poder que se desarrolla en la acción práctica. Cuestiona las bases epistemológicas del plan de estudios, dando lugar a un cruce del eurocentrismo para escuchar las voces que resuenan en América, Asia, África y la diáspora negra, para disipar la ignorancia que nos rodea, matriz de muchas ignorancias y opiniones distorsionadas sobre los temas. de la historia africana y la cultura afrobrasileña. Es dentro de esta perspectiva que se inserta la descolonialidad como una posibilidad de romper las normas sobre lo que se debe enseñar, considerando que el racismo epistemológico ha guiado la construcción, difusión y problematización del conocimiento en el entorno escolar. Por lo tanto, provocar reflexiones sobre la descolonialidad del currículo es una estrategia para combatir el racismo, pensado como un fenómeno estructurante de las relaciones sociales.
\end{abstract}

Palabras clave: Currículum. Decolonialidad. Racismo epistemológico. 


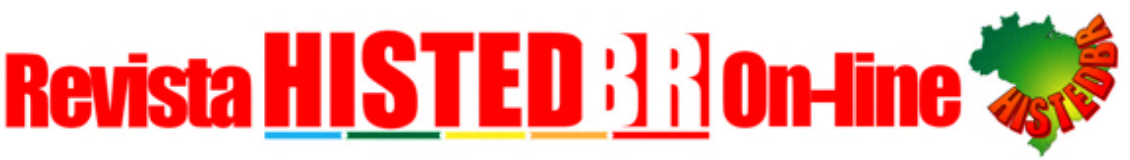

ARTIGO

\section{INTRODUÇÃO}

Certa manhã, nas imediações de uma cidade do sertão baiano, a cerca de $600 \mathrm{~km}$ da capital do Estado, em um ônibus escolar que trafegava pelas estradas vicinais, levando professores, equipe gestora e outros colaboradores para mais um dia de trabalho, ecoava uma interlocução qualquer entre uma diretora e uma coordenadora pedagógica quando, abruptamente, por uma fração de segundos, silenciaram o diálogo, perplexas ao verem um obá numa encruzilhada. E logo pronunciaram sentenças: "Não é de Deus!"; "Como alguém pode se prestar a isso?”. Atentamos menos nos juízos de valor para com as religiões de matriz africana, do que para o fato de essas pessoas, em seu ofício, lidarem com sujeitos, alguns deles, insuspeitamente adeptos dessas religiões.

Diálogos entre o grupo durante a travessia para a escola nas primeiras horas da manhã eram incomuns. Para a maioria, parecia ser preferível madornar ou atentar para a vegetação que ao redor transita da caatinga para o cerrado, emoldurada pelo vale delineado no horizonte. A sonolência e o cansaço, quase sempre típicos dos profissionais no ir e vir cotidiano, talvez tenham inibido uma intervenção. Acresce-se a isso um possível receio em criticar pessoas acima na hierarquia escolar, ou ainda, podemos conjecturar que narrativas dessa ordem se tenham naturalizado de tal maneira que não se percebeu a complexidade do que foi explanado. Não acompanhamos o grupo ao longo do dia, não soubemos se posteriormente houve críticas a essas falas, possivelmente tenham ficado circunscritas ao instante em que foram enunciadas.

Refazendo o mesmo trajeto alguns meses depois, aquela conversação que parecia ter sido encerrada, veio à tona devido à constância com que oferendas são depositadas entre aqueles caminhos. Foi rememorada e ressignificada na fala da diretora, que, apelando para o senso comum, narrava para a coordenadora que aquelas oferendas não tinham, na verdade, nada a ver com o simbolismo místico de matriz africana, afirmando que teria lido em alguma mídia que elas eram uma estratégia dos negros, no passado escravista, que deixavam patuás com comida para os fujões prosseguirem em sua trajetória. De fato, nas redes sociais, em junho de 2016, surgiu um texto atribuído a um professor da UnB que afirmava que as oferendas deixadas nas encruzilhadas eram uma forma de os negros alimentarem seus irmãos escravos que estavam fugindo dos feitores. Não obstante, conforme Gilmar Lopes (2019), o argumento de comida para escravos em fuga não tem sustentação histórica. Aquilo que a diretora leu era, na verdade, uma fake news.

Inquietamo-nos diante do fosso que nos separa de coisas tão próximas, que dizem respeito às nossas raízes culturais, que incorre em descaracterizar as religiões de matriz africana de sua seriedade, validade e de seu caráter de resistência à escravidão, ao preconceito e às assimetrias sociais e econômicas que marginalizam as populações negras. Num contexto marcado pela intolerância religiosa, em que as fake news prestam um desserviço no que tange ao conhecimento cientificamente conduzido, o preconceito contra essas populações e suas expressões culturais leva a desconhecer, de acordo com Stefan 


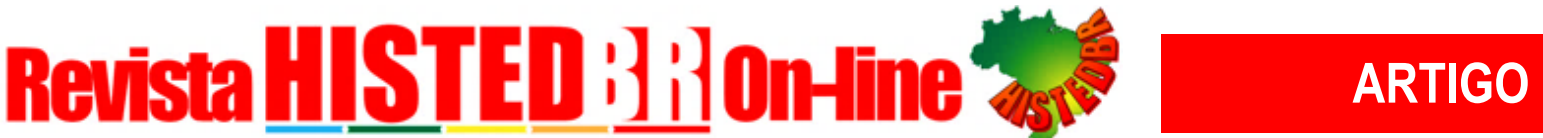

Hubert (2011), por exemplo, que a comida tem um papel crucial no universo das religiões afro-brasileiras. A oferenda, também conhecida popular e pejorativamente como despacho, é uma forma simbólica e ritualística de ligação entre o plano humano e o universo divino dos orixás, um elemento para atingir diversos objetivos, como o de cura e de graça alcançada, pedir proteção espiritual ou simplesmente para agradar às entidades espirituais. (SANTOS, 2005). Não tem nada de demoníaco. A intolerância religiosa e a falta de conhecimento provocam tais reações nas pessoas que não praticam a religiosidade de matriz africana. A oferenda está presente em praticamente todos os momentos, serve de pagamento por favores recebidos ou como resgate de faltas em relação aos preceitos religiosos. Também são chamadas de obrigações e dadas às entidades, por exigência delas, a fim de auxiliarem em questões espirituais e materiais. Leituras interessantes para compreender essas questões podem ser encontradas nos estudos de Norton Figueiredo Correa (2017) e Ideraldo Luiz Beltrame e Marsal Morando (2008).

O episódio narrado demonstra desrespeito, preconceito e desconhecimento, que, partindo de sujeitos que ocupam posições de poder na hierarquia escolar, é denunciador da dimensão do problema. Esses sujeitos são responsáveis por validar em ações práticas a aplicação da Lei 10.639/2003, instrumento importante no combate ao racismo epistêmico no currículo. Portanto, aquele tipo de conversa, se reproduzido em outras circunstâncias, para além de uma conversação restrita ao transporte escolar, pode afetar as relações com os estudantes, principalmente, a sua aprendizagem. Por isso, enfatizamos que a qualificação dos profissionais da educação é um elemento indispensável para combater o racismo.

Trazemos essas experiências para apresentar o propósito deste artigo: problematizar as bases epistemológicas do currículo, ensejando uma travessia do eurocentrismo para ouvir as vozes que ressoam da América, da Ásia, da África e da diáspora negra, no intuito de dissipar o desconhecimento que nos rodeia, matriz de muitas ignorâncias. Mesmo entendendo que a desmistificação que cerca as questões de matriz africana é urgente, percebe-se que o racismo é estrutural na sociedade, ou seja, difícil de ser extirpado.

\section{CURRÍCULO, RACISMO E TEORIA DECOLONIAL}

As experiências relatadas são indicativas da necessidade de compreender o racismo como estruturante das relações sociais. Experiência no sentido de Jorge Larrosa (2002) como algo que nos toca, nos passa, nos acontece, recuperando ainda sua noção heideggeriana, como travessia, perigo, exposição. Quem se permite ou é imposto a experimentar é comparado a um pirata, que se lança ao desconhecido, quer encontrar tesouros, mas não tem certeza do que o aguarda a milhas e milhas do ponto em que se encontra. $\mathrm{O}$ sujeito que participa de uma experiência é tombado, pois ela dele se apodera, requerendo “[...] parar para pensar, parar para olhar, parar para escutar, pensar mais devagar, olhar mais devagar, e escutar mais devagar; parar para sentir, sentir mais devagar." (LARROSA, 2002, p. 24). 


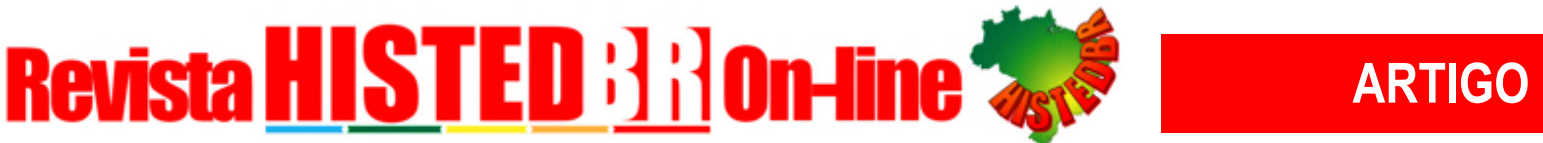

A experiência do racismo na escola nunca fora um problema a inquietar-nos. Questões raciais interferiram em nosso cotidiano e se tornaram um desafio quando, há quatro anos, passamos a interagir com crianças negras em escolas públicas e experenciamos as suas marcas na socialização e aprendizagem delas. Entre as operacionalizações do racismo observadas, podemos relatar a autodepreciação, a autorrejeição de características fenotípicas negróides, baixa autoestima, bullying e outras agressões. Por extensão, desinteresse pela vida escolar e não progressão nos estudos, fatores que, invariavelmente, definem a trajetória escolar e de vida desses sujeitos. Talvez em outra situação as falas da gestão escolar nos teria passado despercebida.

A angústia que advém de problematizar o racismo é a constatação de que sua permanência permeará as múltiplas durações do tempo. (BRAUDEL, 2007). E o combate efetivo desse estigma que nos divide pela linha de cor só será plausível no território da longa duração. 'Essa perspectiva mais longa' é decisiva quando "[...] grupos outrora colonizados tendem a experimentar partes dessa história não como um passado que existe como um traço, mas sim como um presente vivo." (MALDONADO-TORRES, 2019, p. 28). E no que diz respeito à educação, é crucial frisar a importância de os educadores, cotidianamente, nos interstícios das relações de poder, buscarem romper com o racismo epistemológico e institucional, bem como traçar trajetos decolonias autônomos, às margens do que a orientação curricular hegemônica pressupõe. E, certamente, muitos já assumiram essa responsabilidade em suas ações e têm produzido práticas inovadoras.

O termo racismo carrega uma variedade de definições. Antônio Sérgio Alfredo Guimarães, um dos principais pesquisadores que estuda a temática racial no Brasil, aponta diversos significados para a palavra racismo. Em seu livro, Preconceito e discriminação, ele apontou:

(1) Racismo, em primeiro lugar, é referido como sendo uma doutrina, quer se queira científica, quer não, que prega a existência de raças humanas, com diferentes qualidades e habilidades, ordenadas de tal modo que as raças formem um gradiente hierárquico de qualidades morais, psicológicas, físicas e intelectuais.

(2) Além de doutrina, o racismo é também referido como sendo um corpo de atitudes, preferências e gostos instruídos pela ideia de raça e de superioridade racial, seja no plano moral, estético, físico ou intelectual.

(3) Chama-se, ainda, de racismo o sistema de desigualdade de oportunidades, inscritas na estrutura de uma sociedade, que podem ser verificadas apenas estatisticamente através da estrutura de desigualdades raciais, seja na educação, na saúde pública, no emprego, na renda, na moradia etc. (GUIMARÃES, 2004b, p. 17-18).

Rosa Cabecinhas, pesquisadora da Universidade de Minho (Portugal), discute o conceito de racismo e a sua historicidade, revelando os objetivos de seu uso por parte dos grupos sociais hegemônicos.

Ao longo da história, o racismo tem variado muito nos seus alvos (negros, índios etc.), nos mitos que o legitimam (inferioridade intelectual ou moral, 


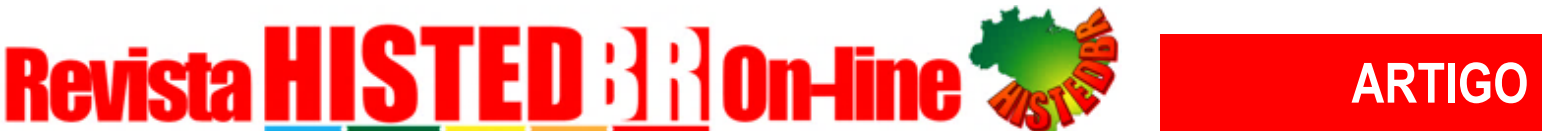

perigosidade, incompatibilidade de culturas etc.), nos interesses que serve (exploração de mão-de-obra, manutenção da pureza racial, preservação da identidade nacional, ...) e nos modos de actuação (extermínio, perseguição, expulsão, segregação ou exclusão simbólica). (CABECINHAS, 2010, p. 19).

No Brasil, segundo considerações de Antônio Sérgio Alfredo Guimarães, a questão racial é um problema nacional amplamente estudado por diversos intelectuais, em momentos e contextos diferentes, a exemplo de Thales de Azevedo, Oracy Nogueira, Florestan Fernandes e Carlos Hasenbalg. Questionando o mito da democracia racial, e evidenciando a complexidade da questão racial brasileira, Antônio Sérgio Alfredo Guimarães afirma que a desigualdade racial e a pretensa diminuição de atitudes racistas são dois lados da mesma moeda.

O nosso desafio atual, ao formar as novas gerações, é teorizar a simultaneidade desses dois fatos aparentemente contraditórios, apontados por todos os que nos precederam: a reprodução ampliada das desigualdades raciais no Brasil coexiste com a suavização crescente das atitudes e dos comportamentos racistas. (GUIMARÃES, 2004a, p. 33).

No Brasil, o fenômeno do racismo é demasiadamente forte, mas, ao mesmo tempo, contraditoriamente, aparece também de forma sutil, velada. Convivem claramente, na sociedade brasileira, um "racismo flagrante" e um "racismo sutil" (NUNES, 2010). No mundo, e evidentemente no Brasil, o racismo tem persistido e tem-se apresentado de diversas formas, com novas roupagens.

Os resultados de diversos estudos recentes mostram que o racismo sofreu uma metamorfose nas suas formas de expressão, mas não desapareceu. As expressões públicas de racismo mudaram muito nas últimas décadas, mas as grandes clivagens entre grupos humanos permanecem. A cor da pele continua a 'marcar' os indivíduos e a determinar oportunidades desiguais. (CABECINHAS, 2010, p. 36).

Partindo do pressuposto de que um racista em algum momento se trairá, a circunstância relatada na introdução deste texto exemplifica as afirmações expressas por Sylvia Nunes (2010) e Rosa Cabecinhas (2010). A conversação daquelas mulheres no transporte escolar evidenciou um racismo flagrante, partindo de profissionais que talvez não tivessem coragem de demonstrá-lo para o restante da comunidade escolar, ou em outros contextos sociais, pois o racismo é condenado socialmente. Assim, estando em um ônibus escolar, entre seus pares, estariam "blindadas", por acreditarem que todos pensariam igual a elas, ou que não fossem passíveis de críticas dadas as suas posições na hierarquia da instituição escolar. Ou ainda, estavam tão envolvidas na conversação que não perceberam que pessoas ao redor estariam ouvindo. Na pior das hipóteses, podem reproduzir essas ideias para toda a clientela escolar, o que repeliria qualquer manifestação em contrário, marginalizando sujeitos que devem ter na escola tratamento equânime. 


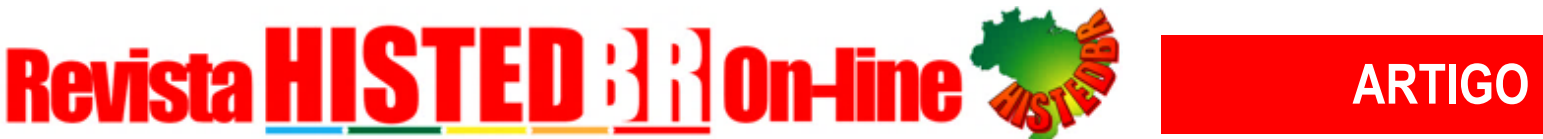

Há escolas que costumam convidar membros de religiões cristãs para se pronunciarem em eventos, e com isso, sob o pretexto do ecumenismo, por um viés sutilmente racista, praticam o proselitismo religioso, afinal parece ser raro que kardecistas ou candomblecistas, por exemplo, tenham recebido convites similares. Verem pessoas com quem possuem afinidades étnicas e religiosas terem papel de destaque no contexto escolar, certamente, seria motivo de empoderamento para os alunos negros ou aqueles que professam outras formas de religiosidade.

E para que na posteridade o racismo seja obsoleto como materialidade a limitar as interações e inserções entre humanos, é crucial promover uma educação antirracista. Essa educação não se concretizará sem nos atermos a aspectos que dizem respeito ao currículo, à decolonialidade, bem como ao racismo epistemológico que impregna o currículo e a produção do conhecimento histórico.

No currículo escolar o racismo se faz presente, por diversas vezes, mascaradamente, por exemplo, ao trabalhar a história da África, afro-brasileira e questões raciais apenas na semana comemorativa do Dia da Consciência Negra; ao adotar materiais como livros didáticos que fazem uma inserção superficial dessas temáticas ou que reproduzam preconceitos e erros históricos como ilustrações de negros representados com deformações físicas; ao tratar atitudes racistas no cotidiano escolar como bullying e não racismo. Não citar negros que não sejam relacionados à escravidão, ao folclórico ou em atividades como a negra do acarajé, o capoeirista, o jogador de futebol. A questão da representatividade ainda é falha, pois as crianças podem internalizar que a elas são restritos apenas esses espaços de atuação. Autores como Ana Célia da Silva (2011), Anderson Ribeiro Oliva (2003), Eliane Cavalleiro (1998) e Kabengele Munanga (2005) tecem considerações pertinentes para refletirmos sobre essas questões no livro didático e no ambiente escolar.

Bell Hooks (2013), ao relatar suas experiências quando estudante e como educadora nos EUA, nos ensina que, para a população negra, o lecionar e o educar eram ações fundamentalmente políticas, pois tinham conexões com a luta antirracista. Ela se referia às escolas de ensino fundamental, no cerne de comunidades negras, com atores negros, contexto onde ela obteve a experiência do aprendizado como revolução. Não obstante, ela observou um deslocamento dessa perspectiva com a integração racial, demonstrando o poder que a instituição escolar obtém na sociedade ocidental, sobretudo, no controle sobre os sujeitos.

A escola mudou radicalmente com a integração racial. O zelo messiânico de transformar nossa mente e nosso ser, que caracterizava os professores e suas práticas pedagógicas nas escolas exclusivamente negras, era coisa do passado. De repente, o conhecimento passou a se resumir à pura informação. Não tinha relação com o modo de viver e se comportar. Já não tinha ligação com a luta antirracista. Levados de ônibus a escola de brancos, logo aprendemos que o que se esperava de nós era a obediência, não o desejo ardente de aprender. A excessiva ânsia de aprender era facilmente entendida como uma ameaça à autoridade branca. (HOOKS, 2013, p. 12). 


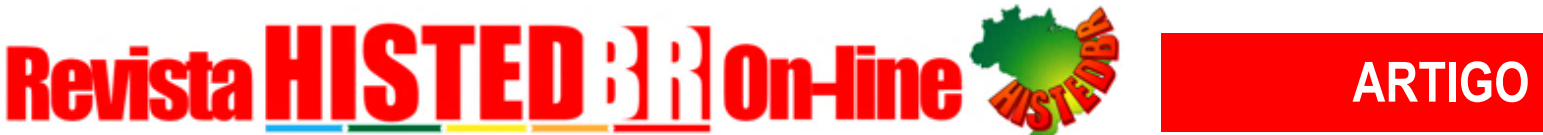

Bell Hooks argumenta que a escola deve valorizar, como política curricular, a diversidade, o respeito às diferenças. No Brasil, as escolas não valorizam a diversidade étnico-racial de forma coerente, com propostas curriculares democráticas. O modelo curricular é ainda, fundamentalmente, tradicional e eurocêntrico.

José Gimeno Sacristán (2000), em O currículo: uma reflexão sobre a prática, alerta para a polissemia que envolve o termo. Todavia, desenvolve uma perspectiva sobre o currículo, entendendo-o como algo que adquire forma e significado educativo à medida que sofre uma série de processos de transformação dentro de atividades práticas. Ou seja, é uma construção social possuindo significado cultural. Essa conceituação desloca-se da experiência para a prática; portanto, na perspectiva do autor, o currículo é práxis/ação antes que um objeto estático. Em linhas gerais ele adverte que o currículo pode ser analisado a partir de cinco instâncias formalmente diferenciadas: 1) do ponto de vista de sua função social, 2) como projeto ou plano educativo, 3) uma extensão formal e material desse projeto, 4) um campo prático, 5) a atividade discursiva acadêmica e pesquisadora sobre todos esses itens. $\mathrm{O}$ fato é que "[...] o currículo não é uma realidade abstrata à margem do sistema educativo em que se desenvolve e para o qual se planeja." (SACRISTÁN, 2000, p. 15).

Nesse contexto, não cabe pensar o currículo como restrito ao rol de conteúdos a serem trabalhados para determinado público. Ele também se refere ao que e quando ensinar. (FELICIANO; ROLKOUSKI, 2017). Compreendê-lo de forma reducionista contribui para que alterações não sejam promovidas, pois pensar o currículo no ambiente escolar é inserilo num campo de tensão em que conflitos políticos, ideológicos, culturais, sociais, econômicos e de identidade encontram materialidade. Enfim, problematizá-lo passa por considerar interesses de segmentos que se agrupam em torno de permanências e dos que reclamam por mudanças.

Dessa forma, propomos pensá-lo na intersecção entre sua concepção de campo de batalha que reflete outras lutas, como corporativas, políticas, econômicas, religiosas, de identidade, culturais, entre outras. (APPLE; BURAS, 2008). Ademais, pensar na perspectiva de "[...] discurso que, ao corporificar narrativas particulares sobre o indivíduo e a sociedade, participa do processo de constituição de sujeitos." (GOMES, 2019, p. 227). Assim, não ingenuamente é que a epistemologia europeia se constitui no alicerce que o orienta, mesmo que, desde meados do século passado, como enfatiza Nilma Lino Gomes (2019), outras epistemologias venham tentando minar as bases e se fazer presentes no espaço pedagógico. É nesse cenário escorregadio e eivado de preconceitos que a Teoria Decolonial se apresenta como uma importante estratégia política de combate ao racismo.

Thais Luzia Colaço, Petter Damázio e Eloíse da Silveira (2012) ressaltam que a teoria decolonial tem origem nos estudos "pós-coloniais". Estes, em geral, datam dos anos $1980 \mathrm{e}$ são tratados a partir de duas perspectivas: a dos Estudos Subalternos, orientados pelo pensamento marxista e movimentos anticoloniais; e os estudos chamados apenas de "póscoloniais". Essas correntes apontam a relação entre os discursos ocidentais e sua afinidade com o poder sobre outras culturas.

\begin{tabular}{l|l|l|l|l|l|}
\hline C Rev. HISTEDBR On-line & Campinas, SP & v.21 & $1-17$ & $\mathrm{e} 021038$ & 2021
\end{tabular}




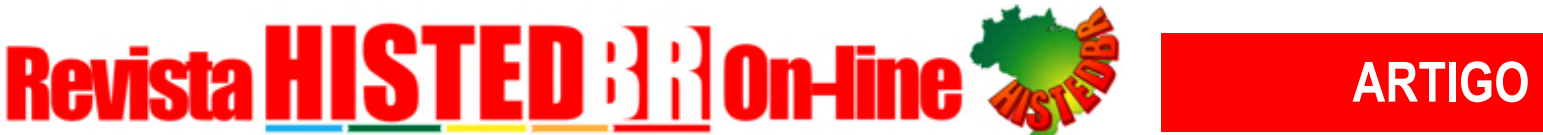

A partir da década de 1990, na América Latina, vêm-se destacando os estudos "decoloniais" ou "descoloniais". Os intelectuais desse movimento possuem um posicionamento de crítica ao colonialismo semelhante aos estudos pós-coloniais que se deram a partir da Índia, entretanto seu ponto de referência é a América Latina. Entre os autores que vêm trabalhando a questão "decolonial" destacam-se: o argentino Walter Mignolo, o sociólogo peruano Aníbal Quijano, o filósofo argentino Enrique Dussel, o filósofo colombiano Santiago Castro-Gómez, o sociólogo porto-riquenho Ramón Grosfoguel, o antropólogo colombiano Arturo Escobar, o sociólogo venezuelano Edgardo Lander, o filósofo porto-riquenho Nelson Maldonado Torres, a linguista estadunidense Catherine Walsh. (COLAÇO; DAMÁZIO; SILVEIRA, 2012, p. 118-119). Entre os objetivos desses pensadores busca-se estabelecer uma noção ampliada de colonialismo para colonialidade, bem como pretendem traçar uma genealogia da decolonialidade e desenvolver um acervo conceitual decolonial, constituindo-se em uma alternativa às grandes narrativas universalistas não apenas para a América Latina, mas para o mundo das ciências sociais e humanas como um todo. Assim, a intenção "[...] é provocar um posicionamento contínuo de transgredir e insurgir. O decolonial implica, portanto, uma luta contínua." (COLAÇO; DAMÁZIO; SILVEIRA, 2012, p. 08). Em outro momento do texto esses autores enfatizam:

[...] A principal força orientadora dos estudos decoloniais é, entretanto, uma reflexão continuada sobre a realidade cultural e política latinoamericana, sendo influenciados decisivamente pelo pensamento filosófico e político desenvolvido no nosso continente. (COLAÇO; DAMÁZIO; SILVEIRA, 2012, p. 120).

Marcilea Andrade e Maurício Reis (2018), no artigo O pensamento decolonial: análise, desafios e perspectivas, enfatizam que a decolonialidade questiona a permanência das condições colonizadas da epistemologia, buscando a emancipação absoluta de todos os tipos de opressão, articulando "[...] interdisciplinarmente cultura, política e economia de maneira a construir um campo totalmente inovador de pensamento que privilegie os elementos epistêmicos locais em detrimento dos legados impostos pela situação colonial." (ANDRADE; REIS, 2018, p. 3). Assim, a decolonialidade suscita questionar o racismo epistemológico presente persistente e continuamente no currículo, pois "[...] o pensamento decolonial reflete sobre a colonização como um grande evento prolongado e de muitas rupturas e não como uma etapa histórica já superada." (COLAÇO; DAMÁZIO; SILVEIRA, 2012, p. 120).

É Nilma Lino Gomes (2019) que nos chama atenção para esse dado ao ressaltar que o movimento e intelectuais negros, atuando inicialmente de forma marginal, trouxeram para as Ciências Humanas e Sociais e para a educação no Brasil a perspectiva negra decolonial, uma das responsáveis pela descolonização dos currículos e do conhecimento no Brasil.

Ainda de acordo com Joaze Bernadino-Costa (2018), essas iniciativas possuem conexões com estudos e ideias desenvolvidas por Du Bois, Guerreiro Ramos e Frantz Fanon, que problematizaram, na academia e em outros espaços, questões raciais, sedimentares para 


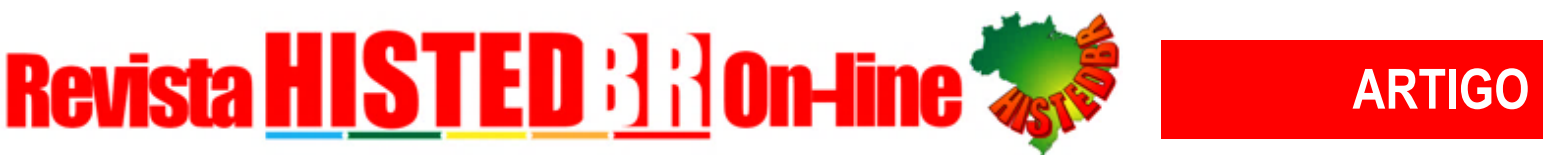

pensarmos o negro como sujeito e não objeto. Pensadores que, apesar de contemporâneos, não dialogaram diretamente e suas ideias demonstram pontos de convergências sobre as questões raciais em seus respectivos contextos históricos. Além de Guerreiro Ramos, é pertinente mencionar os estudos desenvolvidos por outro brasileiro, o sergipano Manoel Bonfim, e suas contribuições para um pensamento divergente sobre o Brasil na história do mundo e da América Latina. Problematizações que se deslocaram posteriormente no fluxo de outras epistemologias, como as desenvolvidas pelos Estudos Culturais, notórias nas contribuições de Stuart Hall, Anthony Appiah e Paul Guiroy, para citar alguns que pensaram as questões raciais de identidade na perspectiva negra. Desde seu surgimento, os Estudos Culturais são espaços alternativos de atuação para fazer frente às tradições elitistas que persistem na distinção hierárquica entre alta cultura e cultura de massa, entre cultura burguesa e cultura operária, entre cultura erudita e cultura popular. (COSTA; SILVEIRA; SOMMER, 2003, p. 37).

O movimento para a inserção da história da África e da diáspora negra no currículo defendido pelos movimentos negros foi decolonial, mas sua concretização nos espaços em que o racismo está institucionalizado tem apresentado entraves em abarcar essa perspectiva renovada do conhecimento, efetivamente descentralizando o currículo do eurocentrismo que historicamente lhe foi peculiar. No Brasil, a Lei 10.639/2003, que impôs a inclusão da história e da cultura africanas e afro-brasileiras, já indicava o baixo interesse da sociedade dita branca, patriarcal e elitista nessas questões, aliás segmento que opera mais no sentido de apagar essas memórias. Dessa forma, o pensamento homogêneo do colonizador marginalizou e suprimiu as epistemologias não europeias, sabotando o diálogo epistêmico com a África, América Latina e Ásia, desvalorizando as produções do conhecimento consideradas subalternas.

Como pertinentemente pondera José Rivair Macedo (2018), incluí-las é crucial para reequilibrar o peso do eurocentrismo em nossa produção histórica, tomando a África menos como objeto e mais como sujeito, enfatizando os conhecimentos produzidos por especialistas em estudos africanos. Ainda é válida a assertiva desse autor quando afirma que, para efetivar uma educação antirracista, é crucial problematizar a própria concepção normativa de história ocidental, eurocêntrica e cristã, confrontando-a com a história dos africanos no continente e na Diáspora Negra: "Trata-se de colocar em discussão a validade dos modelos explicativos do passado e, ao fazê-lo, trazer à tona a questão do racismo epistemológico." (MACEDO, 2018, p. 24).

É por esse viés militante que há uma inclinação para o termo decolonial ao invés de descolonial, pois o primeiro converge para práticas colonialistas que ainda permanecem no cotidiano, mesmo após a descolonização. Portanto, prefere-se o primeiro como um conceito intrínseco ao de libertação. Esse conceito está envolto em dois pontos fundamentais: primeiro, manter a colonização e suas várias dimensões claras no horizonte de luta e, segundo, não perder de vista que a lógica e os legados do colonialismo podem existir mesmo depois do fim da colonização. (MALDONADO-TORRES, 2019). 


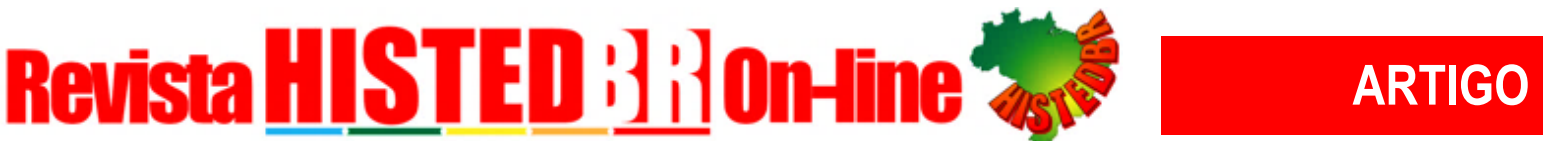

Dessa maneira, a experiência cotidiana em sala de aula permite-nos assegurar a existência de permanências do colonialismo, talvez materializadas no que Tim Ingold (2015) denominou de metodologia rica, que, de fato, não conduz os estudantes a trilhar caminhos outros que não os pré-determinados pelos que ainda ditam as regras. A inserção de conteúdos no currículo, por exemplo, ainda reproduz ideias estereotipadas sobre a África e a diáspora nos livros didáticos. Anderson Ribeiro Oliva alerta para esta questão ao analisar o livro a Nova História Crítica, de Mário Schmidt:

Se, de fato, é um tema negligenciado pelo nosso ensino, por que o autor alerta que sua abordagem será restrita, se sua intenção é valorizar ou minimizar o esquecimento da História da África que fizesse uma análise efetivamente abrangente. Como veremos logo a seguir, se sua coleção possui espaço para tratar a Reforma Religiosa européia em catorze páginas, por que reservar apenas dez para toda a África pré-colonial? Escolha do autor? Da editora? Do mercado consumidor? Dos currículos? (OLIVA, 2003, p. 444-445).

Posteriormente, em pesquisa realizada nos livros didáticos para as séries iniciais do Ensino Fundamental concluída em 2017, constatamos uma série de distorções no que se refere à representação social dos negros nos livros didáticos: abordam a diversidade, mas não problematizam o racismo; reforçam arquétipos estereotipados, enquadrando o negro no espaço do exótico e do folclórico; omitem as trajetórias familiares ao mesmo tempo em que enaltecem o negro na formação da população brasileira; constantemente o associam a ser escravo; atenuam o papel do branco como escravizador; omitem o negro na história narrada nos livros didáticos após a abolição. Dessa maneira, os livros didáticos ainda são racialmente preconceituosos e

[...] refletem uma das tendências do neocolonialismo", ou seja, a tendência de "apagar a memória coletiva dos povos oprimidos". Essas tendências (re)colonizadoras, assim como os movimentos de oposição que visam reescrever geografias nacionais e passados a partir da visão e na língua dos subalternos, envolvem lutas pelo "centro" e pelas "margens". (APPLE; BURAS, 2008, p. 36).

Um assunto que deve ser problematizado e retirado dos livros didáticos, como tema de capítulo, é a expressão "Descolonização da África". Essa expressão, como bem salienta Rubia Caroline e Luis Fernando Cerri (2018), passa a impressão de que não houve luta e resistência por parte dos povos africanos, que a independência, duramente conquistada, foi um ato espontâneo das potências europeias que "desistiram" da colonização e resolveram sair do continente, descolonizando a região. Por isso, torna-se urgente estabelecer uma narrativa que contemple a realidade histórica de forma coerente, rompendo com a história eurocêntrica, com o ensino colonialista.

Desde a Antiguidade, os povos africanos são representados pelos europeus de forma depreciativa e a partir de suas próprias realidades. Esse processo se tornou "institucional" e sistemático no século XX, com o darwinismo social e a pretensa superioridade branca, que vieram junto com a 


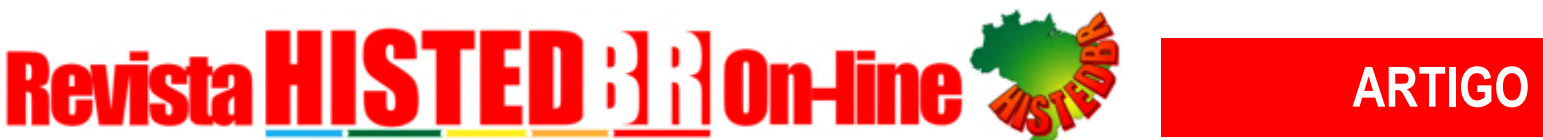

constituição do campo histórico. O desafio está justamente nisso. Romper com uma história "europeizada" que vem sendo contada há mais de um século e estabelecer uma leitura renovada da história do continente africano. (CAROLINE; CERRI, 2018, p. 197-198).

É em tal cenário que o racismo epistemológico ${ }^{1}$ passa, muitas vezes, à revelia de discussões sobre quem tem autoridade para falar no palco das ciências e da educação. Como pertinentemente enfatiza Grosfoguel (2016), o conhecimento elaborado através das experiências sócio-históricas e concepções de mundo "não ocidental" é considerado inferior e é segregado na forma de apartheid epistêmico. É também em virtude do racismo epistêmico que as tradições de matriz africana são ainda vistas com desdém, a exemplo do relatado no início deste texto.

Assim, direcionemos o olhar para as possibilidades de revés que cintilam no horizonte, insinuando que, nas relações de poder conflitantes e em lutas educacionais desiguais, existe uma variedade de limites e possibilidades para uma ação transformadora. (APPLE, BURAS, 2008). E uma das maneiras de favorecer essa luta é minar as bases eurocêntricas do currículo, a partir de práticas "transgressoras", seja na proposição e revisão dos materiais didáticos que existem nas escolas, seja na dimensão do currículo vivido, pois pode haver uma longa distância entre o que se propõe, o que se enseja e o que cotidianamente se realiza. Assim, a questão não é apenas de conscientização, mas de posicionamento político, não basta saber pelo saber, o conhecimento só é válido quando propõe transformar a vida das pessoas para melhor.

Currículo é poder, como bem salientou Miguel Arroyo. Segundo ele, o currículo é um mecanismo de poder, que define o que deve e o que não deve ser estudado: "A escola é disputada na correlação de forças sociais, políticas e culturais.” (ARROYO, 2013, p. 13). Arroyo (2013, p. 13) acrescenta: "Na construção espacial do sistema escolar, o currículo é o núcleo e o espaço central mais estruturante da função da escola. Por conta disso, é o território mais cercado, mais normatizado."

A presença do eurocentrismo no currículo das escolas brasileiras é ainda bem marcante. É preciso e urgente redimensionar o currículo e dar a importância devida, no mesmo grau de relevâncias, aos saberes e conteúdos relacionados, por exemplo, à história da África e da cultura afro-brasileira. O que está em jogo nessa disputa é a construção e divulgação do conhecimento, da narrativa histórica, que tipo de história é consumida pelas crianças e jovens, como ela é contada. Espera-se uma história da África e da cultura afrobrasileira sem visões reducionistas e simplificadas, sem estereótipos (a África pobre e selvagem e os preconceitos em relação às religiões de matriz africana).

Problematizar a história da África e da cultura afro-brasileira nas escolas é algo urgente nos dias atuais, especialmente quando existem vozes que enveredam por um caminho revisionista ou negacionista da história, como a de Fernando Holiday, Vereador de São Paulo eleito pelo DEM em 2016, negro e militante do Movimento Brasil Livre (MBL), que diz que os negros se vitimizam, é contra o Dia da Consciência Negra e diminui a

\begin{tabular}{l|l|l|l|l|l|} 
(C) Rev. HISTEDBR On-line & Campinas, SP & v.21 & $1-17$ & $\mathrm{e} 021038$ & 2021
\end{tabular}




\section{RevistaHISTED Billontine}

importância histórica de Zumbi dos Palmares. Ou declarações polêmicas do jornalista negro Sérgio Camargo, nomeado pelo Presidente Jair Bolsonaro para comandar a Fundação Palmares. Nas redes sociais, e em falas públicas, ele diz que a "escravidão foi benéfica para os descendentes", que os negros se vitimizam, que o racismo no Brasil é "nutella". Ele é contra o Dia da Consciência Negra, negando a importância de Zumbi dos Palmares no contexto de luta contra a escravidão, e pretende, como ação à frente da fundação, "revalorizar" o 13 de maio em detrimento do dia 20 de novembro, enaltecendo a Princesa Isabel e a "atitude cívica" em libertar os escravos².

São discursos e atitudes lamentáveis, especialmente vindos de dois negros que assumem o discurso do colonizador, a ideologia racista do branco, em favor de uma história escandalosamente revisionista. Em função desses abusos do passado, amplamente divulgados nas mídias digitais, que desqualificam a trajetória do negro, e de uma história ainda fragmentada nos currículos e livros didáticos, é que se faz necessário abordar o conhecimento "[...] sobre a África e a trajetória afro-brasileira" de forma a romper com "os estereótipos de inferioridade e de dominação historicamente usados como parte do processo de dominação racial." (CAROLINE; CERRI, 2018, p. 187-188).

Transitar pelos caminhos da contribuição africana para a formação da cultura afrobrasileira, valorizar nossas raízes africanas, é um ato fundamentalmente político, é adotar a estratégia da pedagogia das encruzilhadas, de Luiz Rufino, que, na via conceitual, no campo do currículo e da vida prática, propõe descolonizar o conhecimento para transformar a vidas das pessoas: "[...] a descolonização deve emergir não somente como um mero conceito, mas também como uma prática permanente de transformação social na vida comum, é, logo, uma ação rebelde, inconformada, em suma, um ato revolucionário." (RUFINO, 2019) ${ }^{3}$. Nessa perspectiva, um currículo decolonial pressupõe a valorização dos saberes e das tradições culturais dos invisibilizados da história, os negros:

Sendo assim, é nossa responsabilidade assumir a emergência e a credibilização de outros saberes, diretamente comprometidos, agora, com o reposicionamento histórico daqueles que os praticam. Nessa perspectiva, emerge outro senso ético/estético, os saberes que cruzam a esfera do tempo, praticando nas frestas a invenção de um mundo novo, são aqueles que se encarnam na presença dos seres produzidos como outros. Firmemos nossas respostas combatendo a baixa estima que nos foi imposta, a problemática do conhecimento é fundamentalmente étnico-racial. (RUFINO, 2019).

\section{CONSIDERAÇÕES FINAIS}

Ao longo do texto tentou-se evidenciar a possibilidade do pensamento divergente como uma forma de combater o racismo em suas variadas nuances e que se materializa de diferentes maneiras, em diferentes instituições, o que não seria diferente no espaço pedagógico, arquitetado, experienciado e ressignificado pelo currículo na praxe cotidiana. 


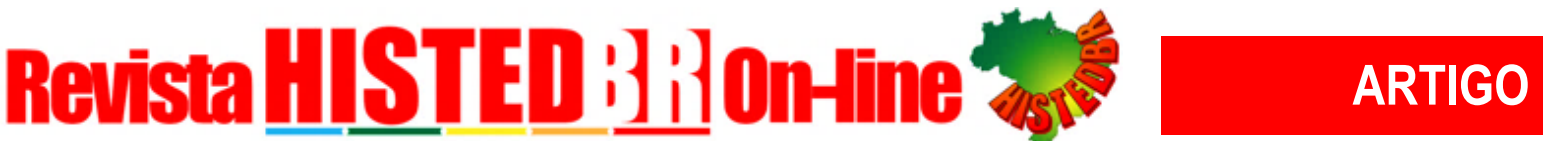

Nesse sentido, os estudos decoloniais, como uma corrente teórica agressiva às epistemologias universalistas e estratégia política de combate ao racismo, criam trincheiras em três campos de luta: a decolonialidade do poder, a decolonialidade do saber e a decolonialidade do ser, que têm que ser passíveis de uma vigilância constante, pois o racismo está estruturado nas relações humanas, não raro, naturalizado, sem que muitas vezes demos conta de que ele está operando em nosso chão social.

Como ressaltou Jorge Larrosa, deveríamos pensar a educação não do ponto de vista da relação entre a ciência e a técnica ou da relação entre teoria e prática, mas propondo que "[...] exploremos juntos outra possibilidade, digamos que mais existencial (sem ser existencialista) e mais estética (sem ser esteticista), a saber, pensar a educação a partir do par experiência/sentido." (LARROSA, 2002, p. 20).

É a partir do binômio experiência/sentido que poderemos pensar alternativas para combater o racismo epistemológico, que perpassa por outras instâncias do vivido. Pôr-se no lugar do outro, conhecer o outro, dialogar com o outro, na verdade se compreender também como outro. Nesse sentido, Tim Ingold chama a atenção para isto: na aprendizagem a etapa mais importante é o processo e não a sua finalização, e questiona: "[...] o conhecimento de fato leva à sabedoria?" (INGOLD, 2015, p. 22). Se pensarmos os conteúdos sobre a África e a forma como os negros estão presentes nos livros didáticos, a incoerência é a alternativa plausível.

Dessa forma, devemos tentar comportar-nos mais como o andarilho, que, no labirinto, se "[...] submete ao mundo e responde aos seus acenos, seguindo por onde outros já estiveram [...] sem começo ou fim, abrindo caminho no fluxo das coisas." (INGOLD, 2015, p. 35). Deve permitir-se aos estudantes experimentar outras estratégias de aprendizagem que, de fato, levem em consideração suas próprias histórias de vida e narrativas coerentes sobre a história da África e da cultura afro-brasileira, o que passa inclusive pelos recursos didáticos presentes na escola e pela forma como os educadores compreendem e trabalham as relações raciais.

\section{REFERÊNCIAS}

ANDRADE, M. F. F. de.; REIS, M. de. N. O pensamento decolonial: análise, desafios e perspectivas. Revista Espaço Acadêmico, Maringá, n. 202, p. 1-11, mar. 2018.

APPLE, M. W.; BURAS, K. L. Currículo, poder e lutas educacionais: com a palavra, os subalternos. Tradução de Ronaldo Catado Costa. Porto Alegre: Artmed, 2008.

ARROYO, M. G. Currículo, território em disputa. 5. ed. Petrópolis, RJ: Vozes, 2013.

BELCHIOR, T. A. do N. Afroperspectividade: por uma filosofia que descoloniza. Entrevista com Entrevista com o doutor em filosofia e professor da UFRRJ, Renato Noguera. Portal Geledes. Seção Artigos e Reflexões, 12 jul. 2015. Disponível em: 


\section{RevistaHIISTED ifilon Hine ARTICo}

https://www.geledes.org.br/afroperspectividade-por-uma-filosofia-que-descoloniza/. Acesso em: 31 jul. 2019.

BELTRAME, I. L.; MORANDO, M. O sagrado na cultura gastronômica do candomblé. Saúde Coletiva, Barueri, v. 5, n. 26, p. 242-248, 2008.

BERNADINO-COSTA, J. Convergências entre intelectuais do Atlântico Negro: Guerreiro Ramos, Frantz Fanon e Du Bois. In: KOMINEK, A. M. V.; VANALI, A. C. (org.).

Roteiros temáticos da diáspora: caminhos para o enfrentamento ao racismo no Brasil. Porto Alegre, RS: Editora Fi, 2018. p. 247-268.

BRASIL. Lei 10.639, de 09 de janeiro de 2003. Altera a Lei no 9.394, de 20 de dezembro de 1996, que estabelece as diretrizes e bases da educação nacional, para incluir no currículo oficial da Rede de Ensino a obrigatoriedade da temática "História e Cultura AfroBrasileira", e dá outras providências. Diário Oficial da República Federativa do Brasil. Poder Executivo, Brasília, DF, 10 jan. 2003. Seção 1, p. 1.

BRAUDEL, F. História e Ciências Sociais: a longa duração. In: Escritos sobre a História. Tradução de J. Guinburg e Tereza Cristina Silveira da Mota. São Paulo: Perspectiva, 2007. p. 261-294.

CABECINHAS, R. Expressões de racismo: mudanças e continuidades. In: GOMBERG, E.; MANDARINO, A. C. de. S. (org.). Racismos: olhares plurais. Salvador: EDUFBA, 2010. p. 11- 43 .

CAROLINE, R.; CERRI, L. F. Treze anos após a Lei n 10.639/03: o que os estudantes sabem sobre a história da África? (Ponta Grossa, 2015). Afro-Ásia, Salvador, n. 57, 187 $211,2018$.

CAVALLEIRO, E. dos. S. Do silêncio do lar ao silêncio escolar: racismo, preconceito e discriminação na educação infantil. São Paulo: Contexto, 1998.

COLAÇO, T. L.; DAMÁZIO, P.; SILVEIRA, E. da. (org.). Novas perspectivas para a antropologia jurídica na América Latina: o direito e o pensamento decolonial. Florianópolis: Fundação Boiteux, 2012.

CORREA, N. F. "A cozinha é a base da religião": a culinária ritual no batuque do Rio Grande do Sul. Arquivos Brasileiros de Alimentação, Recife, v. 2, n. 1, p. 116-127, 2017.

COSTA, M. V.; SILVEIRA, R. H.; SOMMER, L. H. Estudos culturais, educação e pedagogia. Revista Brasileira de Educação, Rio de Janeiro, n. 23, p. 36-61, maio/ago. 2003.

FELICIANO, M. T. F.; ROLKOUSKI, E. Entre o currículo prescrito e o currículo em ação: como professoras do $3^{\circ}$ ano justificam as diferenças em sua prática docente? Acta Scientiae, Canoas, v. 19, n. 6, p. 870-888, nov./dez. 2017. 


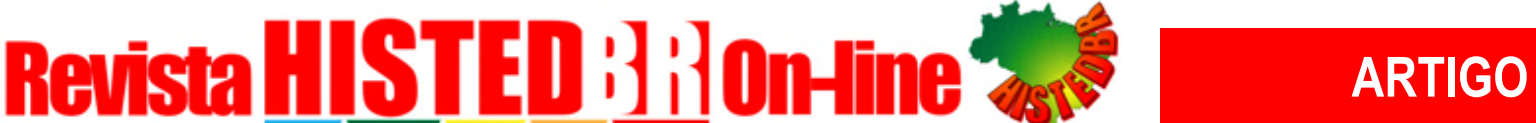

GOMES, N. L. O movimento negro e a intelectualidade negra: descolonizando os currículos. In: COSTA, J. B.; GROSFOGUEL, R.; MALDONADO-TORRES, N. (org.). Decolonialidade e pensamento afrodiaspórico. Belo Horizonte: Autêntica, 2019. p. 223246.

GROSFOGUEL, R. A estrutura do conhecimento nas universidades ocidentalizadas: racismo/sexismo epistêmico e os quatro genocídios/epistemicídios do longo século XVI. Revista Sociedade e Estado, Brasília, v. 31, n. 1, p. 25-49, jan./abr. 2016.

GUIMARÃES, A. S. A. Preconceito de cor e racismo no Brasil. Revista de Antropologia, São Paulo, v. 47, n. 1, p. 9-43, 2004a.

GUIMARÃES, A. S. A. Preconceito e discriminação. São Paulo: Editora 34, 2004b.

HOOKS, B. Ensinando a transgredir: a educação como prática da liberdade. Tradução de Marcelo Brandão Cipolla. São Paulo: Martins Fontes, 2013.

HUBERT, S. Manjar dos deuses: as oferendas nas religiões afro-brasileiras. Primeiros Estudos, São Paulo, n. 1, p. 81-104, 2011.

INGOLD, T. O dédalo e o labirinto: caminhar, imaginar e educar a atenção. Horizontes Antropológicos, Porto Alegre, ano 21, n. 44, p. 21-36, jul./dez. 2015.

LARROSA, J. B. Notas sobre a experiência e o saber de experiência. Revista Brasileira de Educação, Rio de Janeiro, n. 19, p. 20-28, jan./abr. 2002.

LOPES, G. As oferendas do candomblé eram para escravos fugitivos? Disponível em: http://www.e-farsas.com/as-oferendas-do-candomble-eram-para-escravos-fugitivos.html. Acesso: 03 ago. 2019.

MACEDO, J. R. História da África: questões epistemológicas, conceituais e didáticopedagógicas acerca de seu ensino. In: KOMINEK, A. M. V.; VANALI, A. C. (org.). Roteiros temáticos da diáspora: caminhos para o enfrentamento ao racismo no Brasil. Porto Alegre, RS: Editora Fi, 2018. p. 23-47

MALDONADO-TORRES, N. Analítica da colonialidade e da decolonialidade: algumas dimensões básicas. In: COSTA, J. B.; GROSFOGUEL, R.; MALDONADO-TORRES, N. (org.). Decoloniadidade e pensamento afrodiaspórico. Belo Horizonte: Autêntica, 2019. p. 27-53.

MUNANGA, K. (org.). Superando o racismo na escola. 2. ed. Brasília: Ministério da Educação, Secretaria de Educação Continuada, Alfabetização e Diversidade, 2005.

NUNES, S. da. S. Racismo contra negros: um estudo sobre o preconceito sutil. 2010. 227 f. Tese (Doutorado em Psicologia) - Universidade de São Paulo, São Paulo, 2010.

OLIVA, A. R. A História da África nos bancos escolares: representações e imprecisões na literatura didática. Estudos Afro-Asiáticos, Rio de Janeiro, ano 25, n. 3, p. 421-461, 2003. 


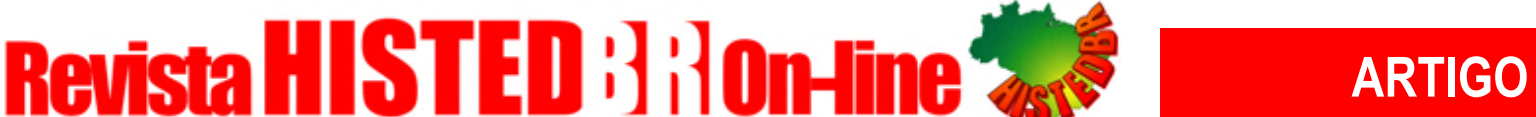

RUFINO, L. Pedagogia das encruzilhadas. Rio de Janeiro: Mórula, 2019.

SACRISTÀN, J. G. O currículo: uma reflexão sobre a prática. 3. ed. Tradução de Ernani F. da Fonseca Rosa. Porto Alegre: Artmed, 2000.

SANTOS, E. C. M. Religião e espetáculo: análise da dimensão espetacular das festas públicas do candomblé. 2005. 229 f. Tese (Doutorado em Antropologia Social) Universidade de São Paulo, São Paulo, 2005.

SILVA, A. C. da. A representação social do negro no livro didático: o que mudou? por que mudou? Salvador: EDUFBA, 2011.

\section{AUTORIA:}

* Doutorado em História Social pela Universidade Federal da Bahia (UFBA). Professor Adjunto da Universidade do Estado da Bahia (UNEB). E-mail: jcnascimento@uneb.br.

** Graduação em Licenciatura Plena em História pela Universidade do Estado da Bahia (UNEB). Professora na Rede Municipal de Educação de Caetité, Bahia (SEC). E-mail: mdcastro696@gmail.com.

COMO CITAR ABNT:

NASCIMENTO, J. C. do; CASTRO, M. A. D. O currículo decolonial e o combate ao racismo epistêmico. Revista HISTEDBR On-line, Campinas, SP, v. 21, p. 1-17, 2021. DOI:

10.20396/rho.v21i00.8657131. Disponível em:

https://periodicos.sbu.unicamp.br/ojs/index.php/histedbr/article/view/8657131. Acesso em: 02 ago. 2021.

\section{Notas}

1 "O racismo epistêmico ou epistemológico é uma das dimensões mais perniciosas da discriminação étnico-racial negativa. Em linhas gerais, significa a recusa em reconhecer que a produção de conhecimento de algumas pessoas seja válida por duas razões: $1^{\circ}$ ) Porque não são brancas; $2^{\circ}$ ) Porque as pesquisas e resultados da produção de conhecimento envolvem repertório e cânones que não são ocidentais.” (NOGUERA apud BELCHIOR, 2015).

${ }^{2}$ Tais assuntos estão amplamente divulgados na web, na imprensa digital (jornais e revistas).

${ }^{3}$ Citação extraída do livro, da seção "A primeira pedra lançada". Lida no site da Amazon Livros, no leitor de livros digitais Kindle. Por isso, não consta a indicação de página. 